(Previously Prace Naukowe

Instytutu Gornictwa Politechniki

Wroclawskiej, ISSN 0370-0798)

ISSN 2300-9586 (print)

ISSN 2353-5423 (online)

Received November 29, 2019; reviewed; accepted September 5, 2020

\title{
STUDY OF THE IMPACT OF EXPLOITATION STRUCTURES ON PRESSURE DISTRIBUTION AND ADSORBED METHANE CONTENT IN COAL SEAMS USING DYNAMIC FLOW MODELS. A CASE STUDY
}

\author{
Wiesław SZOTT*, Krzysztof MIŁEK, \\ Piotr ŁĘTKOWSKI, Andrzej GOŁĄBEK \\ Oil and Gas Institute - National Research Institute, 25 A. Lubicz Str. 31-503 Cracow, Poland
}

\begin{abstract}
One of the most serious difficulties encountered during the estimation of results of various methods of methane drainage from coal seams is the determination of the initial condition of the analysed coal seam prior to commencement of the actual process of methane drainage. It is well known that the exploitation operation in adjacent coal seams, as well as preparatory works in the analysed seam may significantly modify the original state of methane adsorption in that seam, as well as influence the distribution of pore pressure and saturation of its natural fractures with fluids (gas, water). This state is of dynamic nature and depends on a long and complex history of the mining activity in the analysed facility and its surrounding. Detailed specification of the above condition is usually replaced by qualitative and very approximate models, which does not allow for consideration of the process preceding the methane drainage. The subject of the paper is the quantitative evaluation of the initial conditions for a coal seam with the use of dedicated simulation models of the analysed seam along with its broad surroundings. Results of this modelling including modifications of appropriate transport parameters of layers between the seams and their influence on detailed distribution of pore pressures, levels of methane desorption from the coal matrix, directions of reservoir fluids flow (methane, water) and saturation with these fluids in natural fractures of the selected seam, as well as in the pores of overburden and underburden rocks will be thoroughly analysed for determination of spacious and temporal effects of the mining activities in terms of their influence on the selected seam.
\end{abstract}

Keywords: methane drainage, coal seams, exploitation structures, desorption, reservoir simulations

* Corresponding author: szott@inig.pl (W. Szott)

doi: 10.37190/MSC202710 


\section{INTRODUCTION}

Polish coal mines have been extended to ever deeper levels (Annual Report...). As the depth of these seams increases, the amount of the methane adsorbed in them increases as well (Global methane and the coal industry, Krause et al.). That causes exploitation problems limiting the effective time of exploitation in favour of the procedures of methane removal from (ventilation of) mines, also causing serious explosive hazards (Szlązak et al.). A possible solution of these problems is methane drainage of coal seams prior to mining activities (Economic Commission for Europe). These methods involve use of special, typically stimulated boreholes in such seams (Karacan et al. Moore, Lin and Shen, Shen et al., Yan et al., Logan et al., Fourney et al.). The need for them, the density of the performed borehole grid, and particular stimulation techniques are strongly dependent on the initial conditions of these seams, i.e. the conditions before starting the methane drainage process. These conditions, and, in particular, the distribution of pore pressure, fluid saturations and, consequently, the amount of the adsorbed methane is significantly influenced by the presence of adjacent, previously exploited coal seams, as well as the existence of structures allowing for access to these seams (such as gate roads). The changes of pressure and saturations result from fluid flow determined by two factors: (i) pressure gradients induced by exploited zones of highly reduced (atmospheric) pressure and (ii) enhanced transport properties of the analysed seam and other rock layers separating neighbouring seams. The latter are determined by the changes of rock geomechanical state (Kabiesz, Makówka).

This paper presents simulation results of reservoir fluids (water and methane) migration occurring in coal structures performed on a realistic model of one of the coal seams currently planned to be exploited by a national coal company (GasDrain). These results indicate the size of a typical effect of methane drainage and pressure reduction in the analysed seam due to the presence of adjacent, previously exploited seams and other exploitation elements. The size of this effect is strongly dependent upon transport and adsorption properties of coal seams themselves, as well as rocks separating these seams.

This study used Schlumberger software for seam modelling and simulations. In particular, Visage ${ }^{\mathrm{TM}}$ (Visage) for geomechanical simulations and Eclipse ${ }^{\mathrm{TM}}$ (Eclipse) for reservoir fluid (methane and water) dynamic simulations. Visage ${ }^{\mathrm{TM}}$ is a general purpose geomechanical simulator which in particular can be applied to coal structures. Eclipse ${ }^{\mathrm{TM}}$ is a compositional 3D flow reservoir simulator which was originally designed for petroleum structures. However, for several years it has been supplemented by additional specialized modules that cover modelling of all significant mechanisms occurring in coal structures including multiple porosity of coal, methane desorption/adsorption on coal matrix and gas diffusion to natural fracture network. The following coupled simulation procedure using these simulators was applied: first the distributions of geomechanical parameters (stress and strain) were calculated by Visage ${ }^{\mathrm{TM}}$ and the modification of 
transport properties (permeability and diffusion time) were determined. Then, based on obtained results the flow simulations including desorption, diffusion, and viscose flow were performed by Eclipse ${ }^{\mathrm{TM}}$.

\section{CHARACTERISTICS OF THE SIMULATION MODELS}

The studies constituting the subject of this paper were performed with the use of simulations of the phenomena occurring in coal seams conducted on a model of a selected, real structure. These studies used full 3-dimensional geological and geomechanical models of the structure constructed before and presented in the previous paper (Szott et al. 2018). The primary geomechanical state (distribution of stress and strain) of the structure was determined there. That strain was incorporated in initial geomechanical state of the structure before exploitation activities as shown below. For flow studies a 2-dimensional model of this structure corresponding to its vertical cross section and including three coal seams: the one under analysis as well as two adjacent ones - one located above and the other located below the analysed one - and separated from it by shale rocks was constructed. It is shown in Fig. 1.

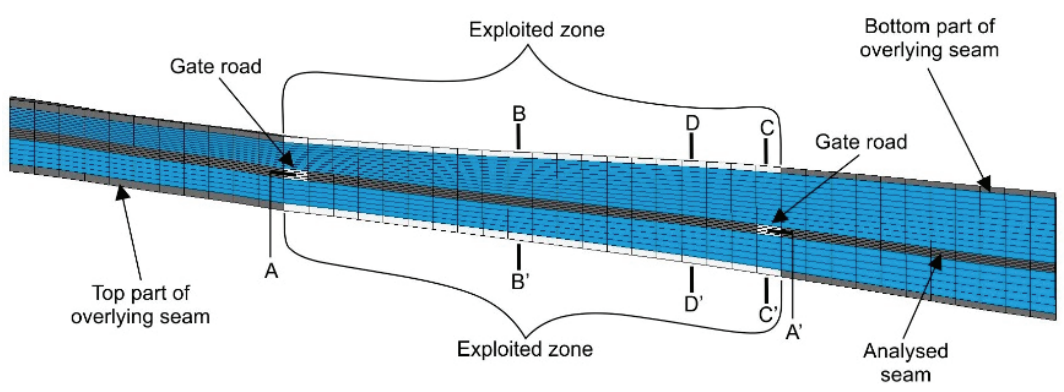

Fig. 1. Vertical, transvers cross-section through the analysed coal seam structure

Significant properties of coal seams (porosity, permeability of fractures, characteristics of methane desorption from coal matrix, coefficient of diffusion from matrix to fractures, matrix-fracture coupling coefficient) were taken from real measurement data performed on coal samples from the tested seams (Kędzior, Krooss et al.). Heterogeneity of porosity and permeability distributions was taken into account with average values of $\phi=0.039, k_{h}=0.27 \mathrm{mD}, k_{v}=0.076 \mathrm{mD}$. The diffusion constant value was $D=8 \times 10^{-6} \mathrm{~m}^{2} / \mathrm{d}$ while the matrix-fractures coupling coefficient was $\sigma=1200 \mathrm{~m}^{-2}$. Typical linear relationships were assumed for relative permeabilities as functions of fluid saturations in coal fractures. Due to the lack of measurement data for basic transport properties of shale layers, uniform values determined in adjacent structures were assumed: porosity $\phi=0.01$, horizontal permeability $k_{h}=0.2 \mathrm{mD}$, vertical permeability 
$k_{v}=0.002 \mathrm{mD}$. In cases analysed below, these parameters were subjected to variations in wide ranges. For relative permeabilities $\mathrm{k}_{\mathrm{rg} / \mathrm{w}}$, of gas/water in the shale layers, typical parabolic dependencies were assumed as functions of relevant saturations $S_{g / w}$ with varying critical saturations of $S_{g c r} / S_{w c r}$ (their base values are $S_{g c r}=0.2$ and $S_{w c r}=0.2$ ). Original distribution of isotropic horizontal permeability in the model of the analysed structure is shown in Fig. 2.
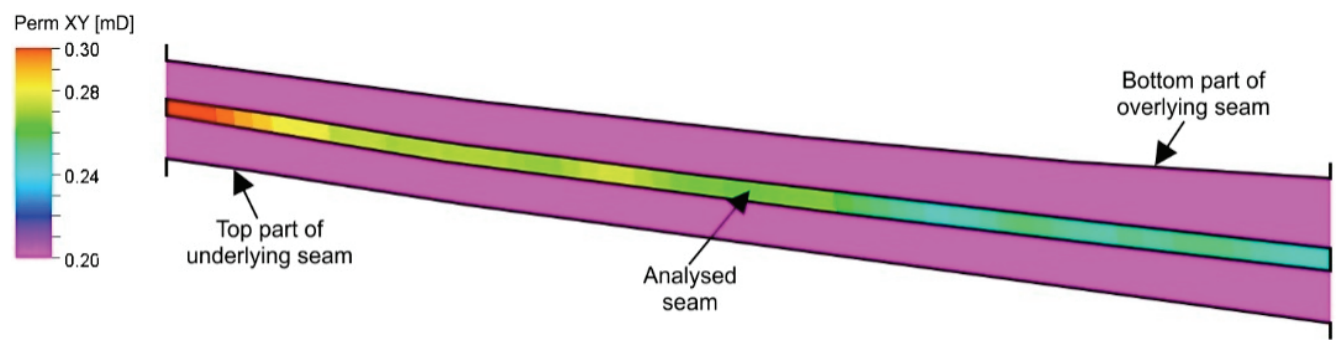

Fig. 2. Horizontal permeability distribution in vertical, transvers cross-section through the analysed coal structure

\section{Initial conditions}

The balanced, hydrostatic distribution of pressure in the structure and 100\% saturation of water in fractures of coal seams and pores of separating layers (shales) were assumed as the initial conditions.

\section{Boundary conditions}

The lack of flow at boundaries of the model as well as normal pressure in the exploited zones were assumed as boundary conditions - depending on the case, it concerns the exploited part of the upper or lower seam as well as the gate roads.

\section{Transport properties from geomechanical state}

Transport properties of the analysed seam and its neighbouring shale layers were modified due to their resultant geomechanical state caused by exploitation activities in the neighbouring seams and the analysed seam itself as given below.

It was assumed that most important variations of the transport properties concerned the diffusion time and permeability modifications, and two distinct zones of geomechanical effects were considered: (i) an intact coal zone with continuous changes in stress and strain redistribution and a (ii) rock (coal) failure zone that was identified by the failure index from the geomechanical modelling.

In the intact coal zone, the permeability modifications were calculated according to the Kozeny Carman model (Bear) as a function of the volumetric strain due to the presence of the exploitation activities: 


$$
\begin{gathered}
\phi=\phi_{0}+\Delta \phi, \\
\Delta \phi=\alpha \varepsilon_{v},
\end{gathered}
$$

and

$$
k_{i}=k_{0 i} \frac{\frac{\phi_{0}^{3}}{\left(1-\phi_{0}\right)^{2}}}{\frac{\phi^{3}}{(1-\phi)^{2}}},
$$

where: $k_{i}$ - modified permeability in the $i$-th main direction, $k_{0 i}$ - initial permeability in the $i$-th main direction, $\phi$ - modified porosity, $\phi_{0}$ - initial porosity, $\Delta \phi$ - change in porosity, $\varepsilon_{v}$ - volumetric strain due exploitation, and $\alpha$ - Biot's coefficient - after (Szott et al. 2018).

In the intact coal zone no variations of cleats density and, consequently, of diffusion time was assumed. In the failure zone, the permeability modifications were calculated according to the Durucan and Shi model (Shi, Durucan) as a function of the diagonal stress components:

$$
k_{i}=k_{0 i} e^{-c \Sigma_{j}^{3}\left[\Delta \sigma_{j}\left(1-\delta_{i j}\right)\right]},
$$

where: $k_{i}$ - modified permeability in the $i$-th main direction, $k_{0 i}$ - initial permeability in the $i$-th main direction, $c$ - permeability compressibility, $\Delta \sigma_{j}$ - change in the effective stress in the $\mathrm{j}$-th main direction, and $\delta_{i j}-$ Kronecker delta.

It is worth noting that modified permeabilities depend on the changes of stress values rather than their absolute values.

In the failure zone, the cleat density and corresponding diffusion time clearly decreased yet no measurements of these variations were available for the analysed structure. It was, however, observed that crushed coal matrix releases adsorbed methane in hours rather than days. Therefore, a reduction of those parameters by approximate factor of one hundred was assumed that corresponds to the diffusion time of ca. 1 day. It was checked that further reduction of the diffusion time did not result in a noticeable variation of the reservoir fluid dynamics in the analysed time scale of months and years rather than days.

\section{IMPACT OF THE EXPLOITED SEAMS ON THE PRESSURE AND CONTENT OF RESERVOIR FLUIDS IN THE ANALYSED COAL SEAM}

Two cases of the model were considered, assuming the presence of the exploited zone in the coal seam located above or below the analysed one. A typical width of this zone 
(hereafter called a production zone) was assumed as $200 \mathrm{~m}$ and a total width of the seam as $400 \mathrm{~m}$.

\section{Results for exploitation of the seam located above}

The case with the exploited zone in the seam located above was considered as a base case. Geomechanical simulations for this case showed no failure zones either in the shale layers or the analysed coal seam. The variations of the volumetric strain for this case is shown in Fig. 3.
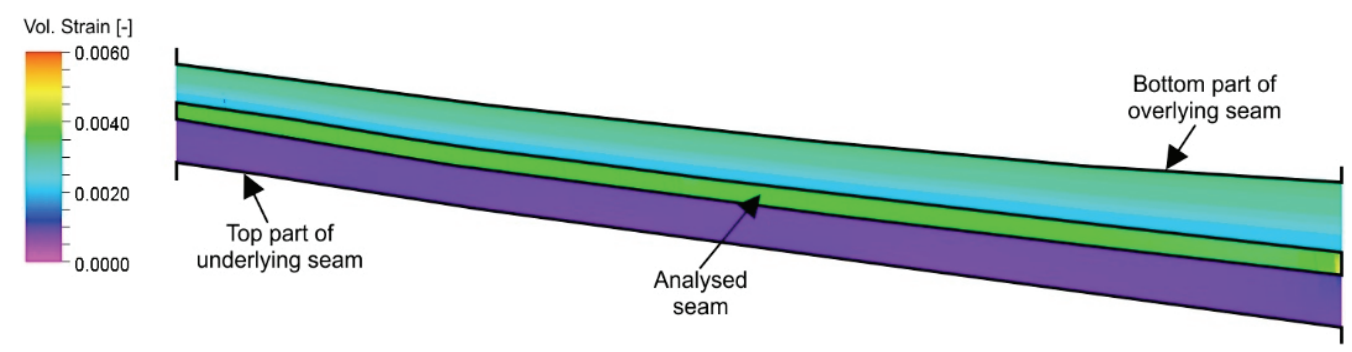

Fig. 3. Volumetric strain distribution in vertical, transvers cross-section through the analysed coal structure. Base case

Modified horizontal permeability distribution resulting from the above volumetric strain according to the correlation presented above is shown in Fig. 4. Analogous modified distribution was obtained for vertical permeability.
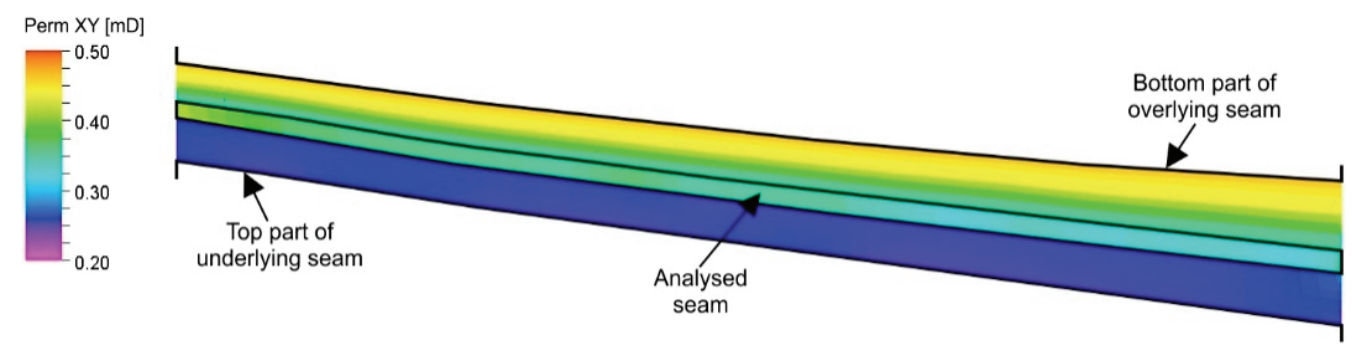

Fig. 4. Horizontal permeability distribution in vertical cross-section through the analysed coal structure. Base case

The presence of the exploited seam was modelled by a normal pressure at its bottom that results in the creation of a pressure gradient causing the migration of reservoir fluids upwards. This flow covers not only the analysed coal seam, but also the layers located below. Firstly, this migration concerns the water originally filling the fractures of the coal seam as well as pores of the separating rocks. In the analysed coal seam, the outflow of water practically disappeared after about $200 \mathrm{~d}$, which is shown 
in Fig. 5, where this outflow was normalized to the unit area of the analysed seam contact with adjacent layers. In the subsequent period, the water outflow from that seam is compensated by its inflow from the layers located below. As a result, the water recovery coefficient in the analysed seam is stabilized at the level of approx. $2 \%$ (Fig. 6).

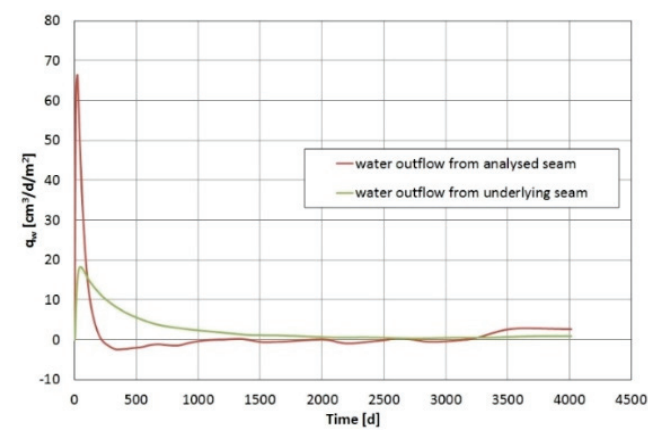

Fig. 5. The outflow of water from the analysed coal seam and the seam located below. Base case

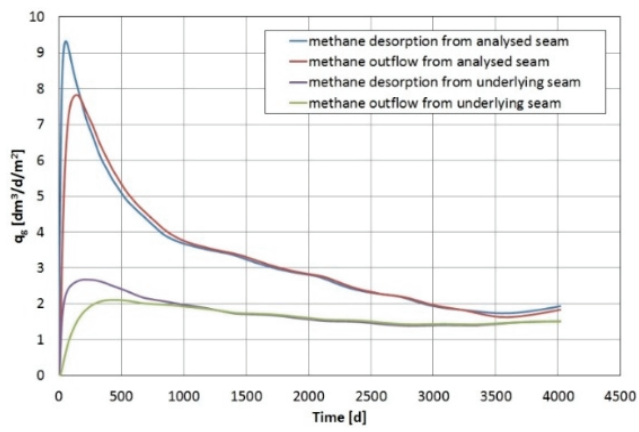

Fig. 7. The desorption and the outflow of methane from the analysed seam and the underlying seam. Base case

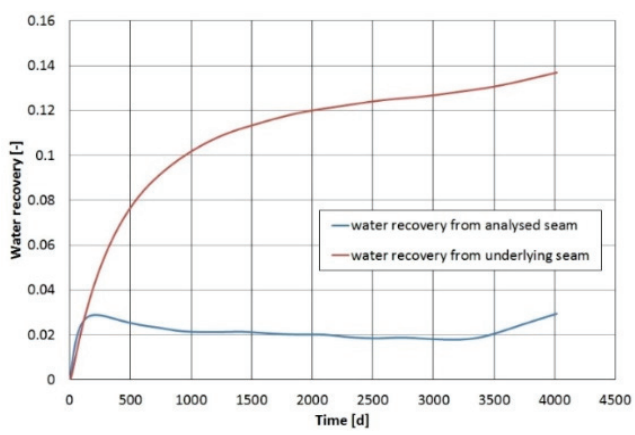

Fig. 6. The water recovery coefficient in the analysed coal seam and the seam located below. Base case

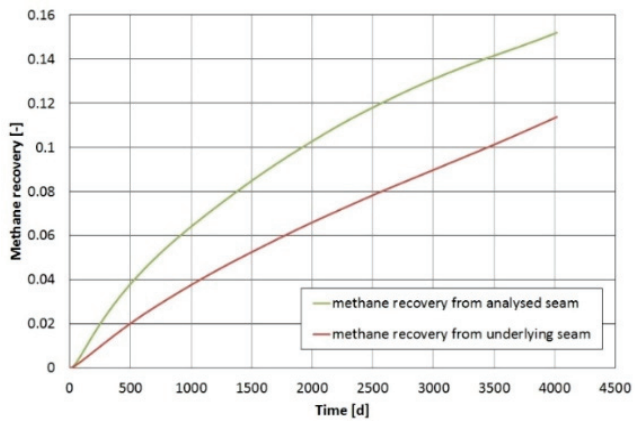

Fig. 8. The methane recovery coefficient in the analysed seam and the underlying seam.

Base case

The pressure drop in the analysed coal seam causes the methane desorption from the coal matrix and its flow to the seam fractures and then through the fractures to the shale rocks located above. This process is presented in Fig. 7, where the intensity of desorption and the size of methane outflow from the analysed coal seam is shown as a function of time. These values reached the maximum after approx. $100 \mathrm{~d}$ from the start of migration and then they gradually reduced. Relatively small difference in the total desorption and outflow of methane from the analysed seam corresponds to small 
$(2 \%)$ gas saturation of its fractures. The final (after 11 years $=4017 \mathrm{~d})$ methane recovery coefficient in the analysed seam caused by the presence of the exploited zone in the seam located above reaches $15 \%$ (Fig. 8).

The detailed pressure distribution in a middle layer of the analysed seam is presented in Fig. 9 for the horizontal cross-section A-A' (defined in Fig. 1) as well as in Fig. 10 for the vertical cross-section B-B' (Fig. 1) through the entire model.

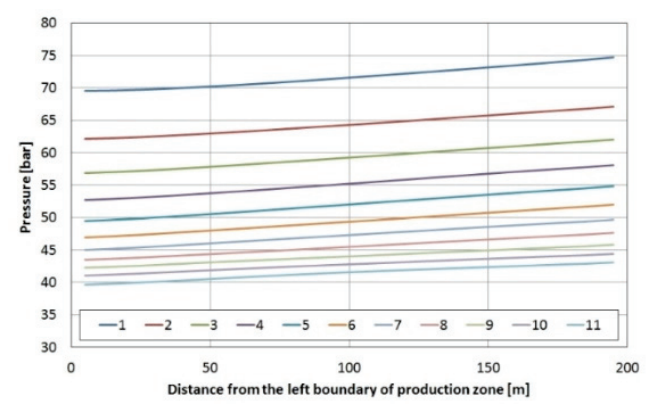

Fig. 9. The pressure distribution in a middle layer of the analysed seam (in horizontal cross-section A-A') for $n=1,2,3, \ldots, 11$ years after the end of exploitation of the seam located above

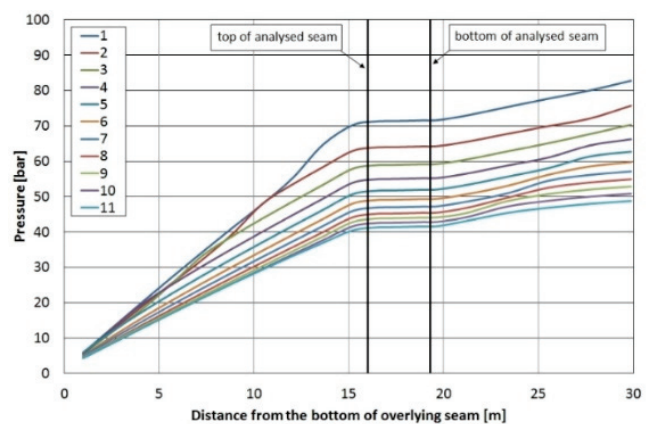

Fig. 10. The pressure distribution in a middle layer of the analysed seam (in the vertical cross-section A-A') for $n=1,2,3, \ldots, 11$ years after the end of the exploitation of the seam located above

The detailed distribution of free gas (methane) saturation within a middle layer of the analysed seam is presented in Fig. 11 for the horizontal cross-section A-A' as well as in Fig. 12 for the vertical cross-section B-B' through the entire model.

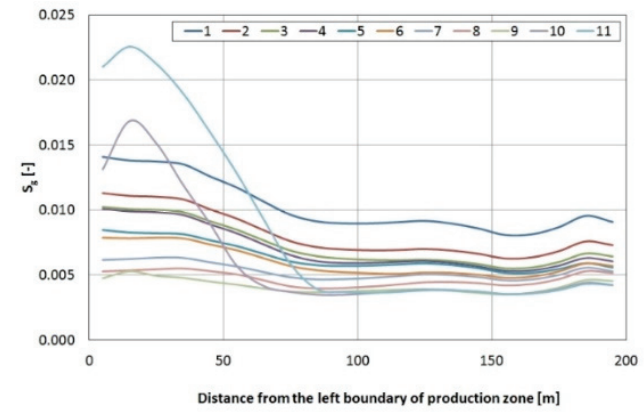

Fig. 11. The free gas saturation distribution within a middle layer of the analysed seam (in the horizontal cross-section A-A') for $n=1,2,3, \ldots, 11$ years after the end of the exploitation of the seam located above

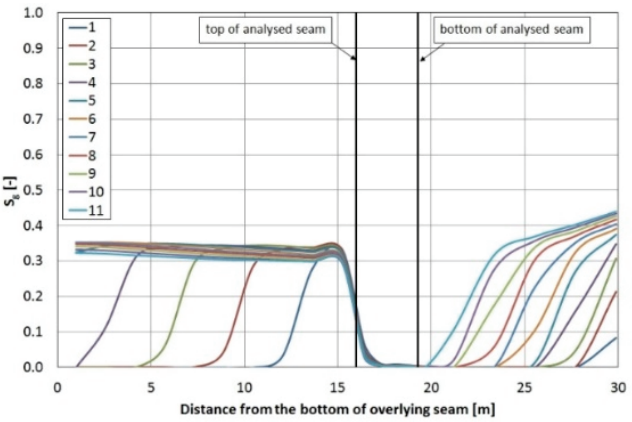

Fig. 12. The free gas saturation distribution within a middle layer of the analysed seam (in the vertical cross-section B- $\mathrm{B}^{\prime}$ ) for $n=1,2,3, \ldots, 11$ years after the end of the exploitation of the seam located above 
Detailed distribution of pressure as well as the reservoir fluids saturations across the entire model is presented in Fig. 13.

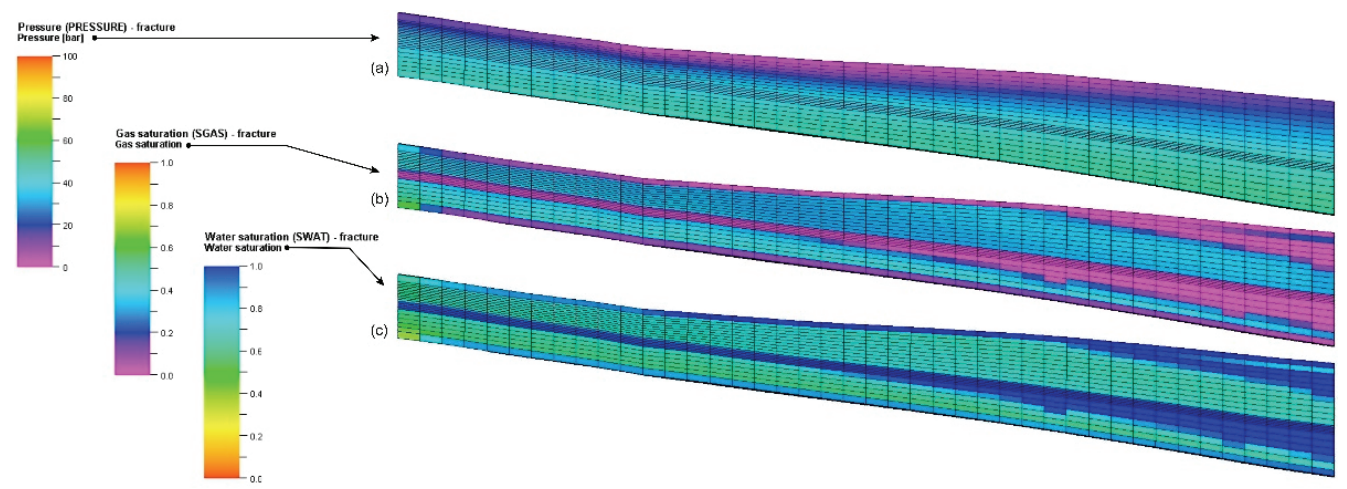

Fig. 13. The distribution of pressure (a) and saturation of free reservoir fluids - gas (b) and water (c) in the vertical, transverse cross-section of the analysed structure. Base case.

Results after $t=11$ years ( $4017 \mathrm{~d}$ ) after the end of exploitation of the seam located above

\section{Results for exploitation of the seam located below}

For comparative purposes, an analogical simulation was performed for the case with the exploited zone in the seam located below. Geomechanical simulations for this case also showed no failure zones either in the shale layers or the analysed coal seam. As in the previous case no failure zones were obtained in this case. The variations of the volumetric strain for this case is shown in Fig. 14.
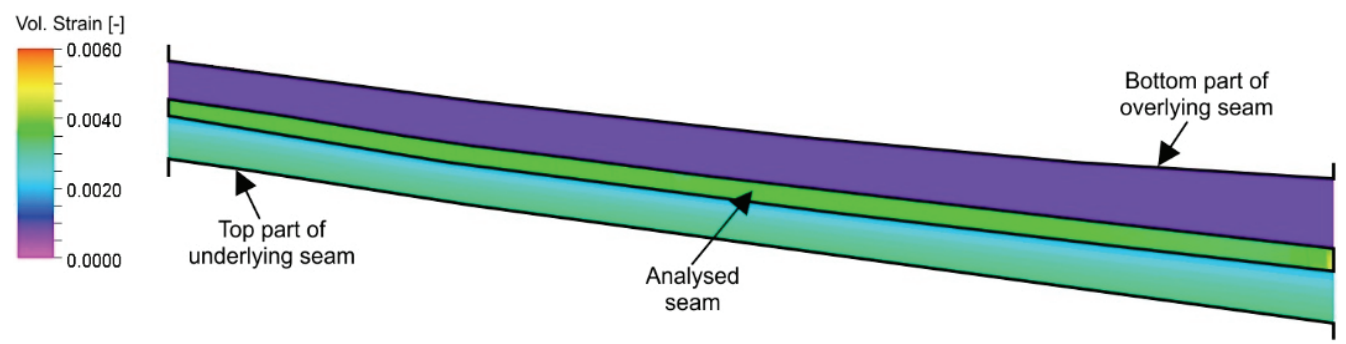

Fig. 14. Volumetric strain distribution in vertical, transvers cross-section through the analysed coal structure. Case of exploitation seam below

Modified horizontal permeability distribution resulting from the above volumetric strain according to the correlation presented above is shown in Fig. 15. Analogous modified distribution was obtained for vertical permeability. 

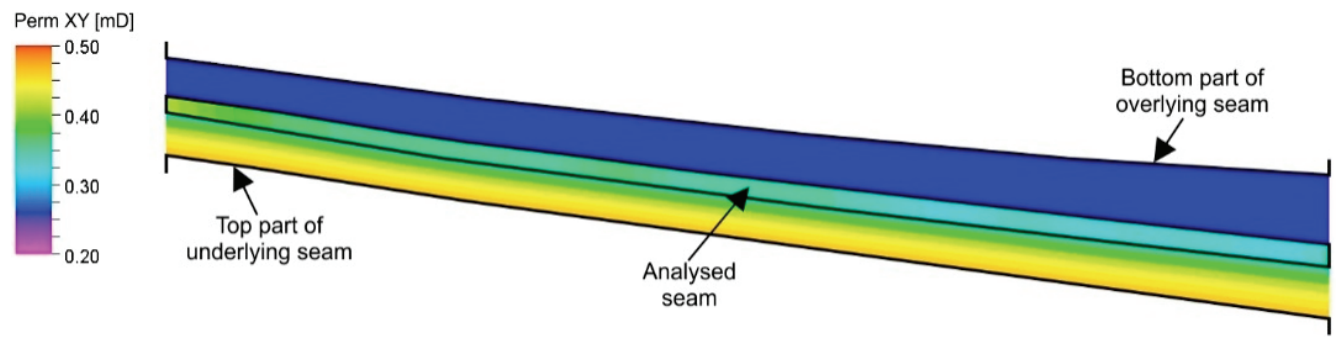

Fig. 15. Horizontal permeability distribution in vertical, transvers cross-section through the analysed coal structure.

Case of exploitation seam below

The presence of the exploited seam was modelled by a normal pressure at its top that results in the creation of a pressure gradient acting against the natural effect of buoyancy force for gas and enhancing natural gravitational forces for water. As a result, more intensive outflow of water from the analysed seam compared to the previous case occurs (Fig. 16). As a result, the degree of water depletion from fractures of the analysed seam is significantly higher compared to the previous case and reaches almost 50\% (Fig. 17).

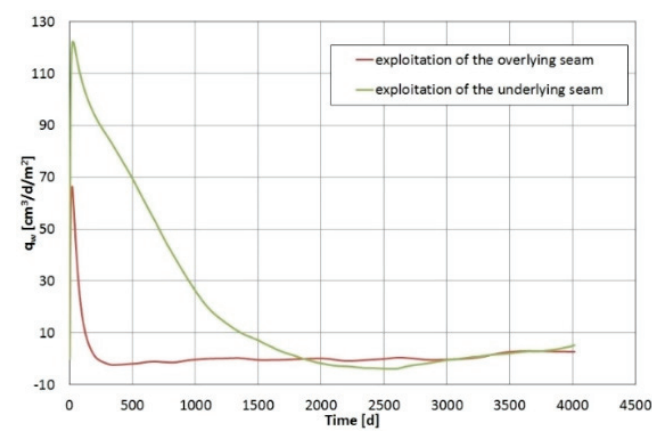

Fig. 16. The outflow of water from the analysed seam.

The result of exploitation of the adjacent seams (located above or below)

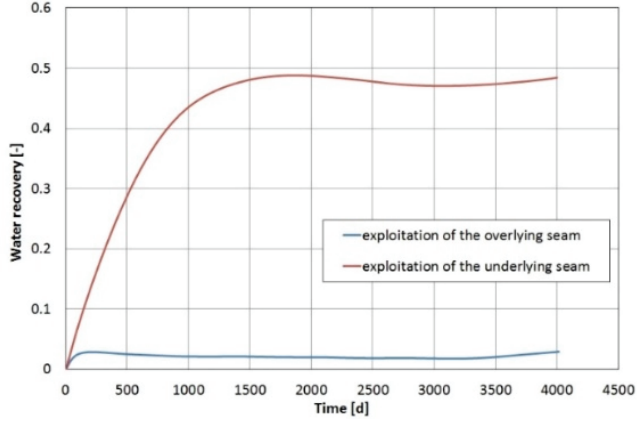

Fig. 17. The recovery coefficient of water in the analysed seam.

The result of exploitation of the adjacent seam (located above or below)

The outflow of methane from the analysed seam is characterized also by a different time profile compared to the base case (Fig. 18). In turn, the methane recovery coefficient is approximately equal to the one for the base case and it amounts to almost $17 \%$ at the end of the simulated period (Fig. 19). 


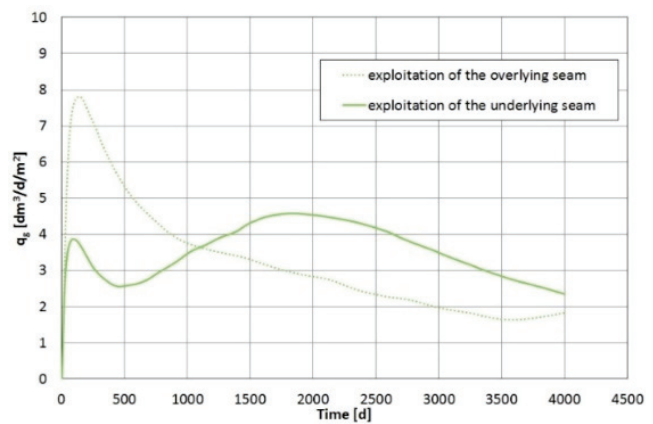

Fig. 18. The outflow of methane from the analysed seam. The result of exploitation of the adjacent seam (located above or below)

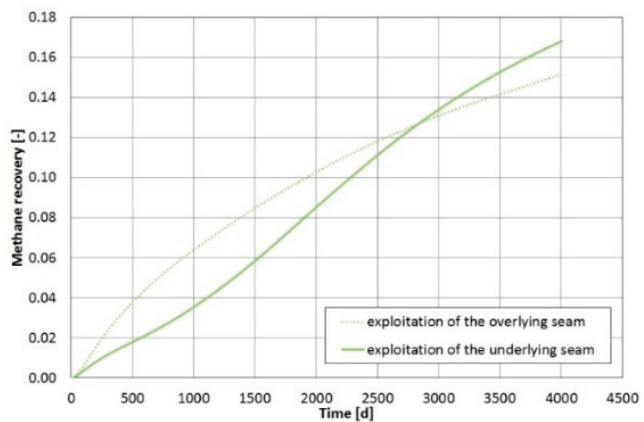

Fig. 19. The methane recovery factor in the analysed coal seam.

The result of exploitation of the adjacent seam (located above or below)

\section{THE ANALYSIS OF MAIN RESULTS SENSITIVITY WITH RESPECT TO THE PROPERTIES OF ROCKS SEPARATING THE SEAMS}

Due to incomplete information concerning the basic transport properties of shale layers separating coal seams, the analysis of sensitivity of the basic simulation results for changes of these properties was performed. Three parameters with potentially highest influence on the results of the simulations were considered:

- vertical permeability of shales-variability within the range of $k_{v}=0.02-$ $0.0002 \mathrm{mD}$,

- critical gas saturation in shales-variability within the range of $S_{g c r}=0.1-0.3$,

- critical water saturation in shales-variability within the range of $S_{w c r}=0.1-0.3$.

The remaining characteristics of the model corresponded to the base case (with the production zone in the seam located above).

\section{Sensitivity due to $\boldsymbol{k}_{v}$}

The value of the vertical permeability of shales significantly influences the changes of pressure and fluid saturations in the analysed seam. Its increase to the value of $k_{v}=0.02 \mathrm{mD}$ causes a significant increase of methane outflow from the analysed seam (Fig. 20), which results in relatively high degree of methane recovery coefficient depletion of the seam amounting to $55 \%$ at the end of the simulated period (Fig. 21). On the other hand, the reduction of the vertical permeability to the value of $k_{v}=0.0002 \mathrm{mD}$ significantly reduces the methane outflow (Fig. 20) as well as its recovery coefficient (Fig. 21) with the final value of $4 \%$. 


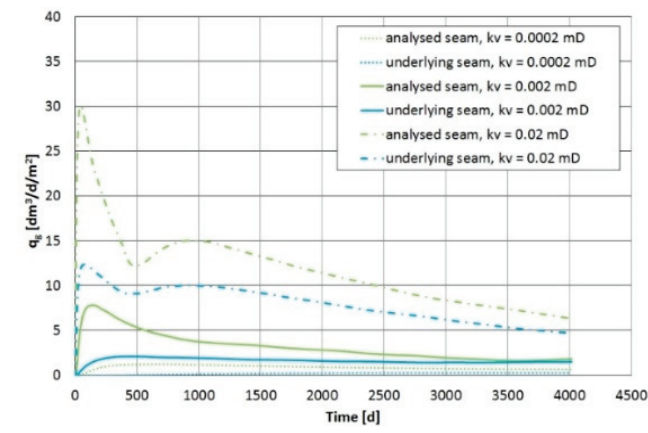

Fig. 20. The outflow of methane

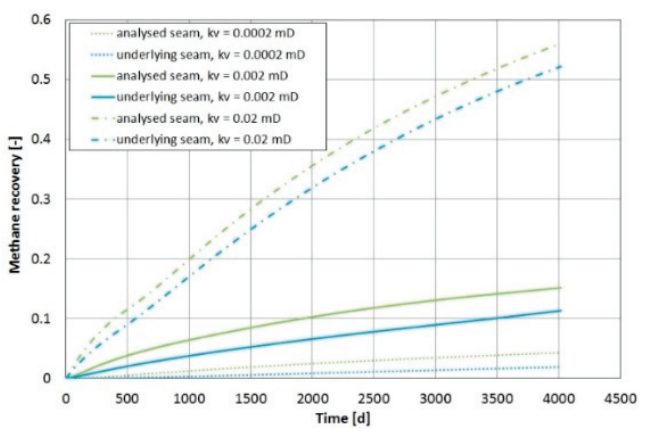

Fig. 21. The methane recovery coefficient from the analysed seam and the seam located below. in the analysed seam and the seam located below.

Dependency on vertical permeability, $k_{v}$, of separating layers

Dependency on vertical permeability, $k_{v}$, of separating layers

\section{Sensitivity due to $S_{g c r}$}

The value of a critical gas saturation in shales has significantly smaller impact on changes of the pressure and gas saturation in the analysed seam, especially in the initial phase of the reservoir fluids migration. These changes result in relatively small differences in methane outflow from the analysed coal seam (Fig. 22) which entails also relatively small changes of the methane recovery coefficient of the seam (Fig. 23).

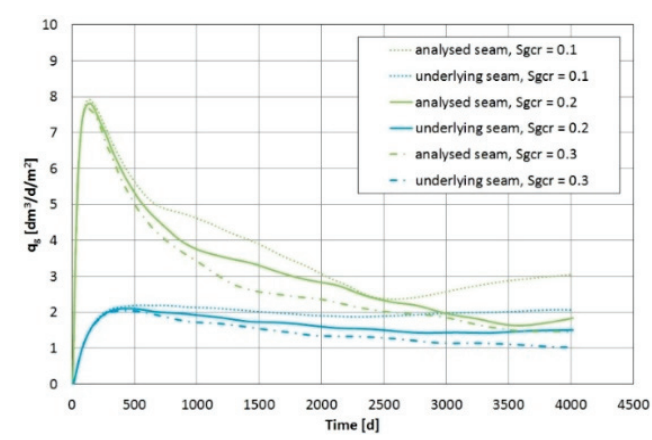

Fig. 22. The outflow of methane

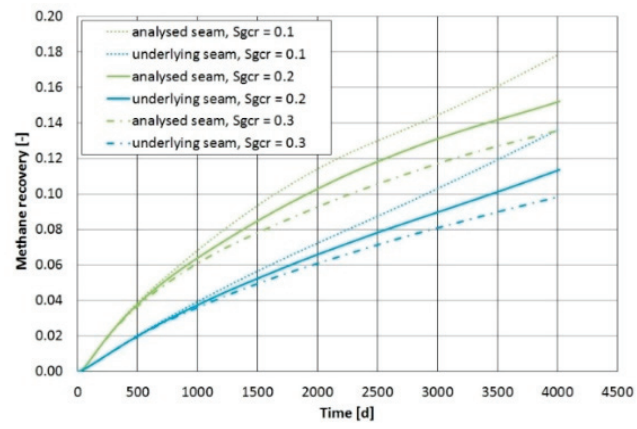

Fig. 23. The methane recovery coefficient in separating layers

from the analysed seam and the seam located below. in the analysed seam and the seam located below.
Dependency on the residual gas saturation, $S_{g c r}$, Dependency on the residual gas saturation, $S_{g c r}$,

from the analysed seam and the seam located below. in the analysed seam and the seam located below.
Dependency on the residual gas saturation, $S_{g c r}$, Dependency on the residual gas saturation, $S_{g c r}$, in separating layers

\section{Sensitivity due to $S_{w c r}$}

The changes of the critical water saturation, $S_{w c r}$ in shales in the specified range has practically no effect on the distribution of pressure and reservoir fluids saturations within the entire volume of the analysed structure. It results from the fact related to the initial condition for reservoir fluids saturation - both fractures of the coal seams and 
pores of the shale rocks are completely saturated with water so that their transport properties are only slightly dependent on $S_{w c r}$.

\section{THE IMPACT OF GATE ROADS ON THE PRESSURE DISTRIBUTION AND CONTENT OF RESERVOIR FLUIDS}

The presence of the exploited coal seams in vicinity of the analysed seam may influence the condition of this seam in extremely diverse way. This influence depends mostly on the proximity of the exploited seams as well as detailed transport properties of layers separating these seams from the analysed one, which was presented in the above analysis. In case of large distances and low permeabilities of separating rocks, this influence can be even completely neglected. Contrary to the above situation, gate roads are always present in the coal seam to be exploited. By definition they are in a direct contact with the exploited zone of the seam and their impact is not dependent on the presence and properties of the separating rocks. Moreover, direct contacts of gate roads with the analysed zone of the seam may cause, and usually causes, the geomechanical disturbances of this zone. Geomechanical simulations for this case resulted in the occurrence of failure zones in the direct neighbourhood of gate roads as shown in Fig. 24a.

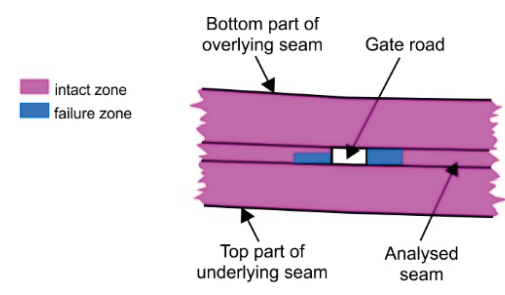

(a) Failure vs intact zone

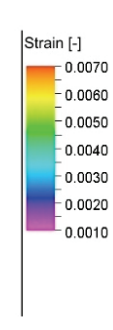

Fig. 24. Distribution of failure zones (a) and volumetric strain (b) in vertical, transvers cross-section through the analysed coal structure around a gate road
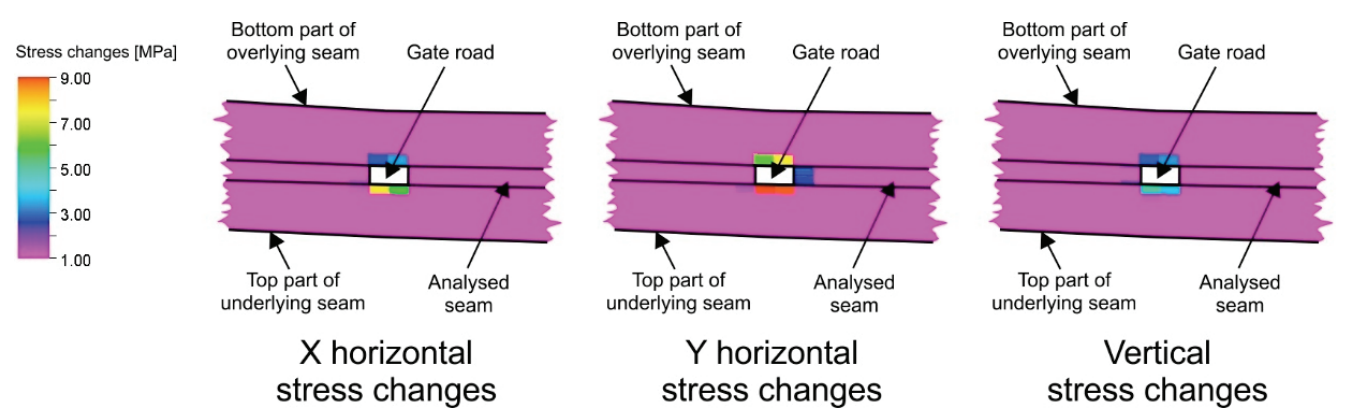

Fig. 25. Changes of main stress tensor components in vertical, transvers cross-section through the analysed coal structure around a gate road 
The presence of gate roads caused volumetric strain modifications as shown in Fig. 24b, and changes of the stress tensor as shown in Fig. 25.

Resulting permeability distribution modifications were obtained by applying appropriate correlations given above. Modified permeability distributions are shown in Fig. 26.

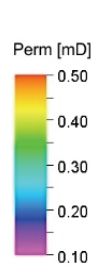

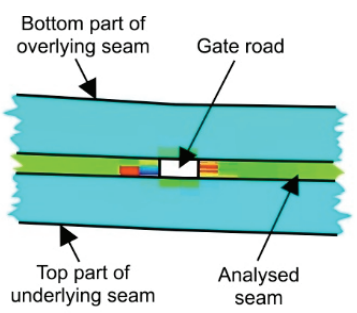

Permeability $X$

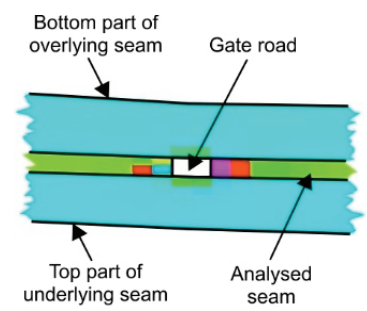

Permeability $Y$

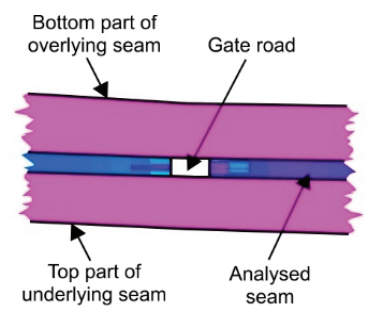

Permeability $\mathbf{Z}$

Fig. 26. Permeability vector distributions in vertical, transvers cross-section through the analysed coal structure around a gate road

Another characteristic property of exploitation structures taken into account in the model is time of their influence on the analysed seam. This time amounts usually to years for the adjacent exploited seams and to months for the gate roads. In the results of the simulations presented below, there were assumed 5 years of influence of the adjacent seams before the occurrence and start of the influence of the gate roads.

Presence of the gate roads causes the occurrence of high horizontal pressure gradients (Fig. 27) in the zone of the analysed coal seam planned to be exploited. They are responsible for fluids flow to these gate roads and this flow is stable over time. On the other hand, vertical gradients of pressure are subject to a more complex change. In the

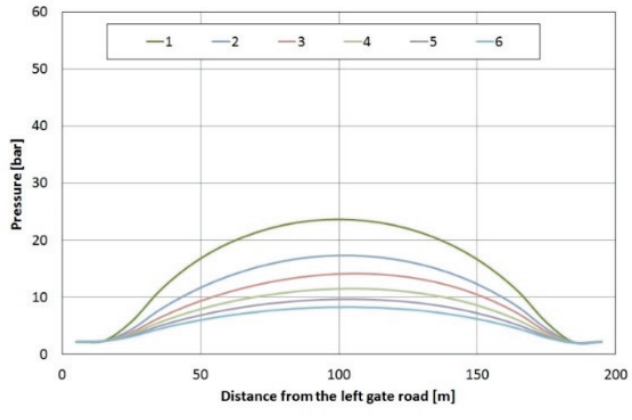

Fig. 27. The pressure distribution in a middle layer of the analysed zone (in horizontal cross-section A-A') for $n=1,2, \ldots, 6$ years after the completion of the gate roads

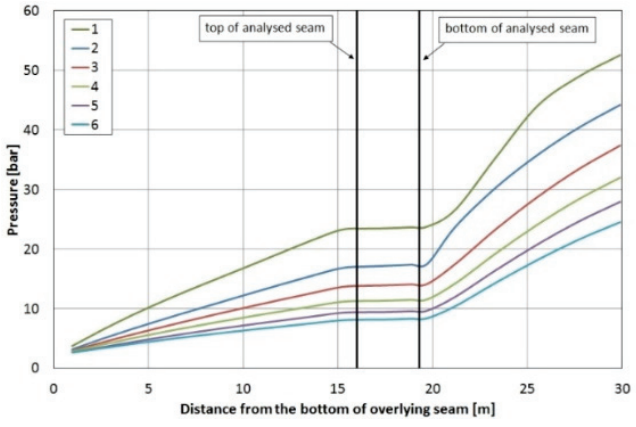

Fig. 28. The pressure distribution in the model of the analysed structure (in vertical cross-section B-B') for $n=1,2, \ldots, 6$ years after the completion of the gate roads 
middle of the analysed zone, these gradients does not change directions, but are reduced within and above the analysed zone as well as increased (especially in the initial period) below this zone (Fig. 28).

In the gate roads and their vicinity, the vertical pressure gradients change their directions, causing the fluid flow to gate roads both from the above and below located layers (Figs. 29 and 30).

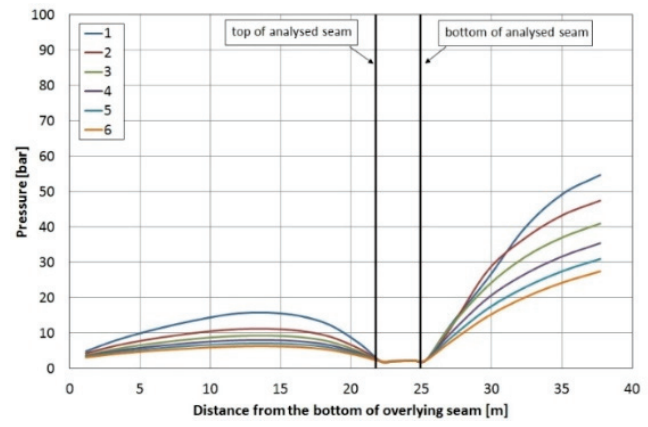

Fig. 29. The pressure distribution in the model of the analysed structure (in vertical cross-section C-C') for $n=1,2, \ldots, 6$ years after the completion of the gate roads

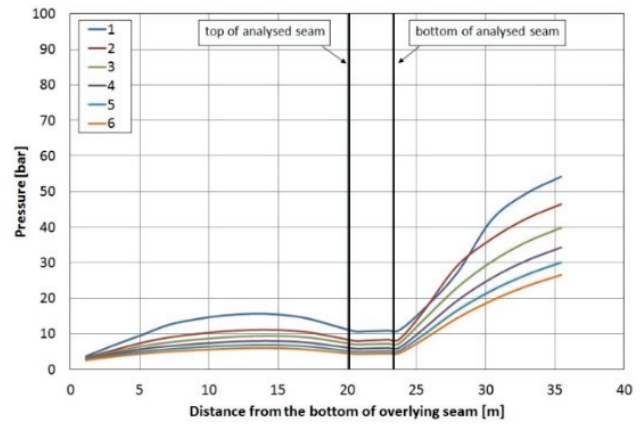

Fig. 30. The pressure distribution in the model of the analysed structure (in vertical cross-section D-D') for $n=1,2, \ldots, 6$ years after the completion of the gate roads

Changes of reservoir fluid saturations are also reported that affects fluids relative permeabilities. The gas saturation increases (and water saturation decreases) in the analysed seam (Fig. 31) especially in its top layers (Figs. 32 and 33).

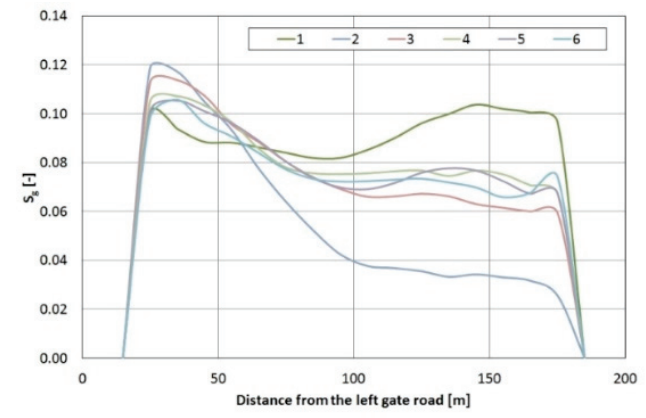

Fig. 31. The gas saturation distribution in a middle layer of the analysed zone (in horizontal

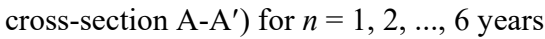
after the completion of the gate roads

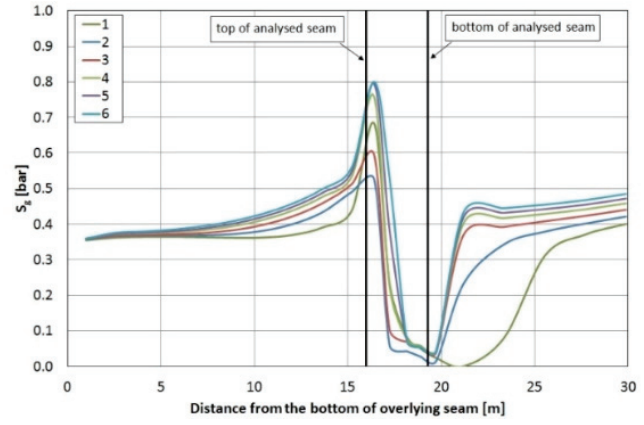

Fig. 32. The gas saturation distribution in the model of the analysed structure (in vertical cross-section B-B') for $n=1,2, \ldots, 6$ years after the completion of the gate roads 


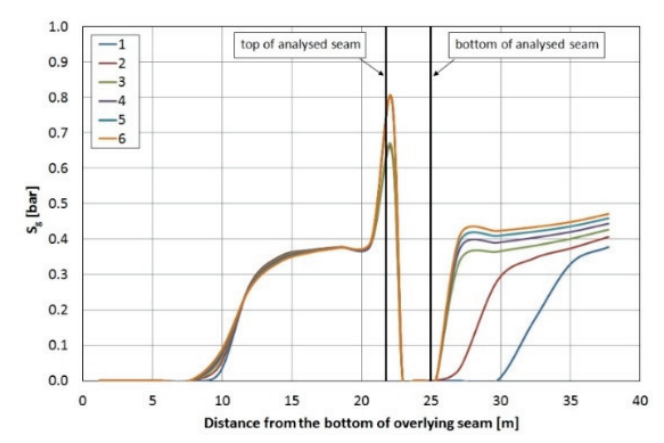

Fig. 33. The gas saturation distribution in the model of the analysed structure

(in vertical cross-section C-C') for $n=1,2, \ldots, 6$ years after the completion of the gate roads

As a result of the above changes of both factors (pressure gradients and reservoir fluid saturations), the presence of the gate roads causes initially a rapid outflow of gas as well as water from the analysed zone to the gate roads (Figs. 34 and 35). Flow of gas between the analysed zone and the layers located above initially changes the direction (inflow of gas to the zone takes place) and restores the original direction of outflow after several hundred of days. This outflow significantly decreases, however, by the end of the analysed period, the share of horizontal flows (to the gate roads) in the gas drainage of the analysed zone predominates over the share of vertical flows (to the upper layers) - Fig. 34. In the case of water, its outflow from the analysed zone to the gate roads (Fig. 35) is also predominant at first, but after a few years the direction of water flow changes (net inflow of water to the analysed zone) due to the predominant contribution of the layers located both above and (especially) below the analysed seam (Figs. 35 and 37).

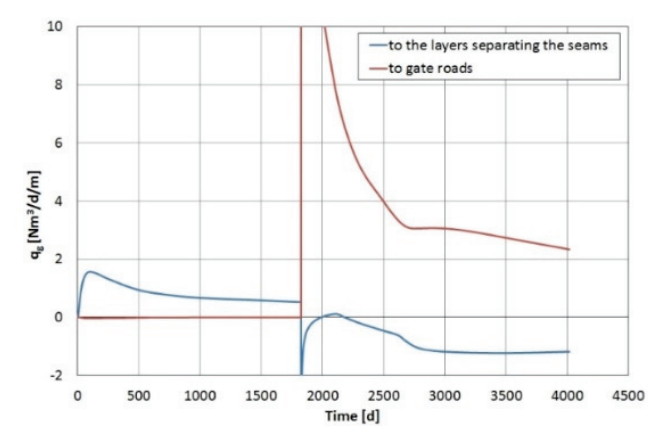

Fig. 34. The outflow of gas from the seam zone planned for exploitation

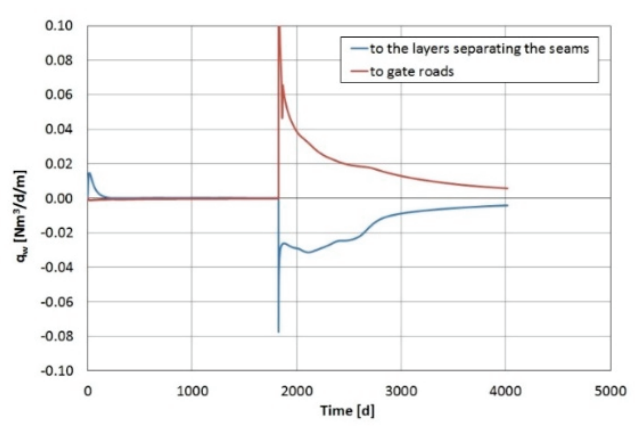

Fig. 35. The outflow of water from the seam zone planned for exploitation 


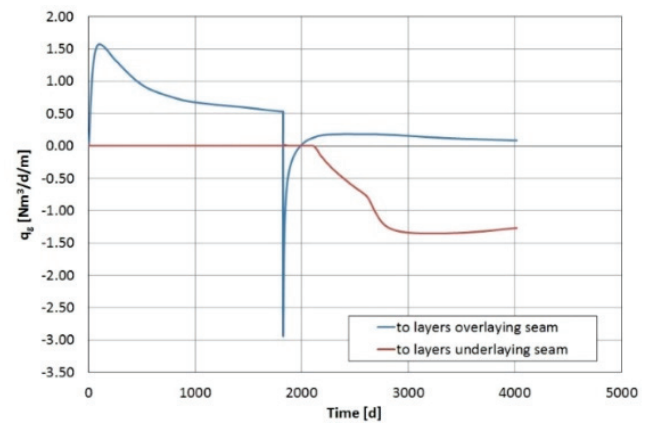

Fig. 36. The outflow of gas from the seam zone planned for exploitation to separating layers

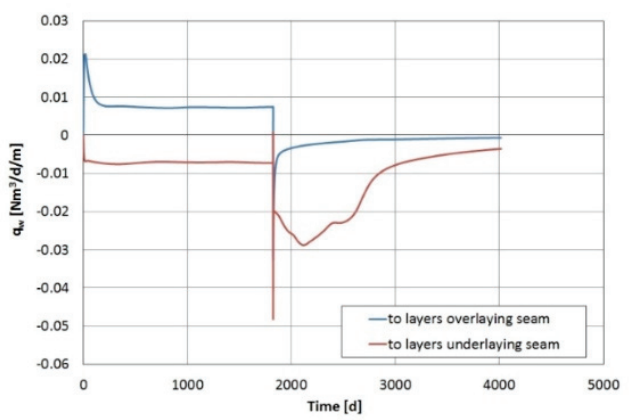

Fig. 37. The outflow of water from the seam zone planned for exploitation to separating layers.

The flows described above result in a significant increase in the recovery coefficient of both gas (Fig. 38) and water (Fig. 39) in the zone planned for exploitation of the analysed coal seam. The gas recovery coefficient amounts to $40 \%$ after one year ( $t=6$ years from the beginning of the analysis) of the gate roads influence and exceeds $60 \%$ after 6 years ( $t=11$ years from the beginning of the analysis). On the other hand, the water recovery coefficient of water depletion amounts to approx. $22 \%$ after the year of the gate roads influence and reaches $30 \%$ after 6 years.

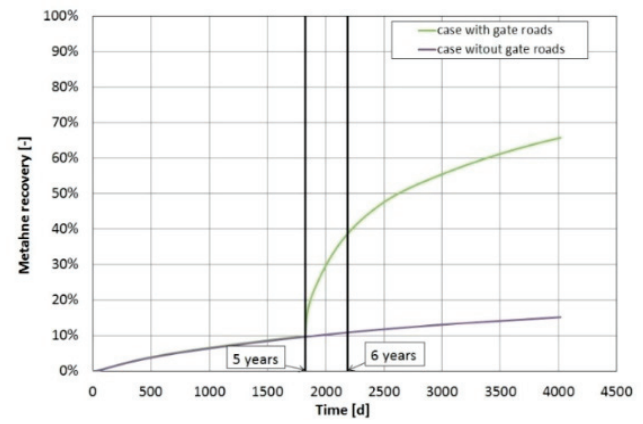

Fig. 38. The gas (methane) recovery coefficient in the zone planned for exploitation of the analysed coal seam

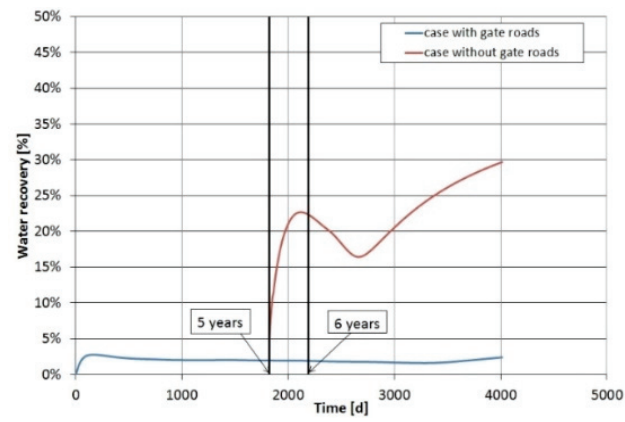

Fig. 39. The water recovery coefficient in the zone planned for exploitation of the analysed coal seam

It should be emphasized that the gas outflow (methane drainage) of the zone planned for exploitation in the analysed seam is the sole effect of the gas desorption process from the coal matrix of this zone, which in turn is a delayed (due to the finite diffusion time) function of pressure reduction in the zone. Detailed, strongly heterogeneous distribution of this pressure and distribution of reservoir fluids are shown in Fig. 40. The average value of this pressure decreases over time as shown in Fig. 41. 


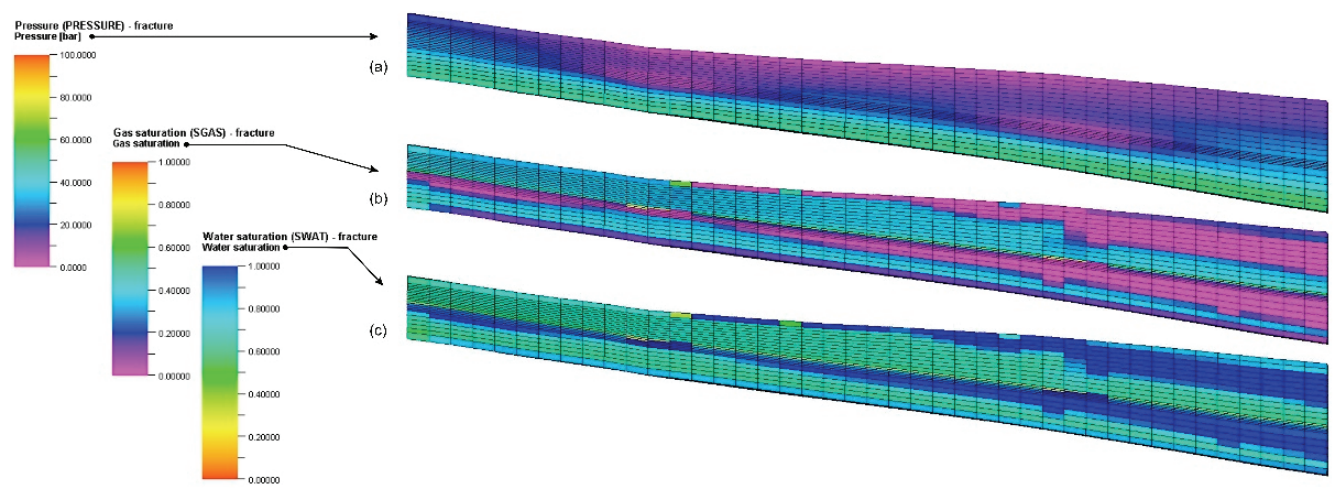

Fig. 40. The distribution of pressure (a) and saturation of free reservoir fluids - gas (b) and water (c) - in the vertical, transverse cross-section of the analysed structure. The case with the exploited seam located above and presence of the gate roads. Results after 1 year from the completion of the gate roads, after 6 years of analysis

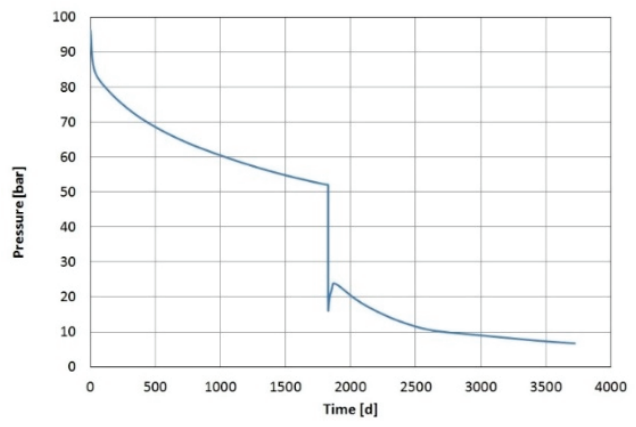

Fig. 41. The change of average pressure with time in the zone planned for exploitation of the analysed seam

Water drainage of the zone planned for exploitation in the analysed seam is slightly dependent on the pressure (due to low compressibility of water) and it is mainly a function of water saturation in the fractures of the zone.

\section{SUMMARY AND CONCLUSIONS}

On the basis of an example of a realistic structure of coal seams, the possibility of performing a detailed quantitative evaluation of pressure and reservoir fluids distributions in a selected coal seam caused by the exploitation activities in neighbouring seams as well as preparation works (gate roads) in the selected seam was presented. For this purpose, simulation models that take into account the analysed coal seam 
together with adjacent seams and the layers separating these seams are found of practical value. Simulations of these models have to include all the basic processes that occur in the analysed structure as a consequence of the exploitation activities, i.e., the desorption of methane from the coal matrix, its diffusion to the system of fractures of coal seam and viscous, two-phase gas and water flow in the system of these fractures as well as in the porous medium of rocks separating coal seams. The results of such simulations turn out to be strongly depend on the geometry and properties of all the component of the structure.

The detailed simulation results obtained for the structure under the study allow us to formulate the following conclusions and remarks:

- taking into account the existence of exploitation structures in coal seams is crucial to correctly determine the initial condition of the analysed coal seam prior to the start of the proper process of methane drainage - the presence of such structures may result in up to $50 \%$ reduction of methane content in the analysed seam,

- conducted simulations indicate the dominant influence of the presence of gate roads in the coal seam on the state of its initial pressure distribution and methane drainage - the key parameters for a correct description of the occurring phenomena are: parameters of the methane desorption process (desorption isotherm) in coal matrix, time of diffusion from the matrix to coal fractures and their permeability; it should be noted that values of diffusion time and permeability of fractures are functions of the geo-mechanical state of the analysed seam which may be significantly disturbed by the presence of exploitation structures, in particular, gate roads,

- the presence of exploited, adjacent coal seams may also influence the condition of initial pressure distribution and methane content of the analysed seam to an extent depending on the parameters of the structure, in particular its geometry and transport properties of the rocks separating coal seams - its quantitative assessment requires rather detailed knowledge of these properties and may lead to a very complex character of the reservoir fluids flow (in particular, partial reversal of flow directions),

- in order to precisely take into account the influence of the exploitation structures on the condition of pressure distribution and methane drainage in the coal seam, it is necessary to take into account the full, detailed history of the exploitation of previously exploited, adjacent seams and other exploitation structures.

\section{ACKNOWLEDGEMENTS}

This research was carried out as part of the project: Badania wplywu struktur eksploatacyjnych na dynamiczny rozkład ciśnień $i$ wielkości zaadsorbowanego metanu $w$ poktadach węgla przy pomocy modeli 
geomechanicznych i dynamicznych modeli przeplywów, [Research on the influence of exploitation structures on the dynamic distribution of pressures and quantities of adsorbed methane in coal seams with the use of geo-mechanical and dynamic flow models] which is funded by the Ministry of Science and Higher Education; archival case number: DK-4100-97/17, INIG-PIB internal order number: 110/KZ.

\section{REFERENCES}

Annual Report... 2002-2011 - Annual Report (for the years 2001-2010) on the State of Basic Natural and Technical Hazards in the Hard Coal Mining Industry, Gas Hazard. Publ. Central Mining Institute, Katowice 2002-2011, p. 20-40.

BEAR J., 1972, Dynamics of fluids in porous media, Dover Publications.

Eclipse 300, 2017, GeoQuest, Schlumberger, https://www.software.slb.com/products/eclipse, [accessed: 15 May 2017].

Economic Commission for Europe, 2010. Methane to Markets Partnership. Best Practice Guidance for Effective Methane Drainage and Use in Coal Mines, ECE Energy Series No. 31, United Nations, New York and Geneva.

FOURNEY W.L., BARKER D.B., HOLLOWAY D.C., 1981, Model studies of explosive well stimulation techniques, International Journal of Rock Mechanics and Mining Sciences and Geomechanics Abstracts, Vol. 18, Iss. 2, pp. 113-127, ISSN 0148-9062,

GasDrain - Development of Improved Methane Drainage Technologies by Stimulating Coal Seams for Major Risks Prevention and Increased Coal Output), 2018, Project funded by the European Commission Research Programme of the Research Fund for Coal and Steel under grant agreement No. RFCR-CT-2014-00004, Consortium led by Central Mining Institute, Katowice, Poland, 01.07.201431.12.2018.

Global methane and the coal industry, 1994, Coal Industry Advisory Board, International Energy Agency, Paris.

KABIESZ J., MAKÓWKA J., 2009, Empirical-analytical method for evaluating the pressure distribution in the hard coal seams, Mining Science and Technology, 19, pp. 556-562.

KARACAN C.Ö., DIAMOND W.P., SCHATZEL S.J., 2007, Numerical analysis of the influence of inseam horizontal methane drainage boreholes on longwall face emission rates, International Journal of Coal Geology, 72, 15-32.

KĘDZIOR S., 2015, Methane contents and coal-rank variability in the Upper Silesian Coal Basin, Poland, International Journal of Coal Geology, 139, 152-164.

KRAUSE E., WIERZBIŃSKI K., SIMKA A., 2005, Intensity of gas desorption from the coal as indicator of methane and rock outburst hazard, Quarterly "Mine rescue", No. 3 (39).

KROOSS B., LEŚNIAK G., AMANN-HILDENBRAND A., ZIEGER L., ZIEMIANIN K., 2016, RWTH Aachen University, unpublished Deliverable No. 1.1 Characterisation of Coal Seams and Surrounding Rocks: Field Site Characterisation, Project: Development of Improved Methane Drainage Technologies by Stimulating Coal Seams for Major Risks Prevention and Increased Coal Output (GasDRAIN) funded by the European Commission Research Fund for Coal and Steel (RFCS), Grant No: RFCR-CT-2015-00005).

LIN B., SHEN C., 2015, Coal permeability-improving mechanism of multilevel slotting by water jet and application in coal mine gas extraction, Environ Earth Sci., 73, 5975-5986.

LOGAN T.L. et al., 1993, Optimizing and Evaluation of Open Hole Cavity Completion Techniques for Coal Gas Wells, Proceedings of the 1993 International Coalbed Methane Symposium, The University of Alabama/Tuscaloosa, 9346.

MOORE TA., 2012, Coalbed methane: A review, International Journal of Coal Geology, 101, 36-81.

Package: Eclipse 100, 300, Release 2014.1, Petrel Release 2014.1. GeoQuest Schlumberger. 
SHEN C. et al., 2015, Analysis of the stress-permeability coupling property in water jet slotting coal and its impact on methane drainage, Journal of Petroleum Science and Engineering, 126, 231-241.

SHI J., DURUCAN S., A model for changes in coalbed permeability during primary and enhanced methane recovery, SPE Reservoir Evaluation and Engineering, 2005, 8, 291-299.

SZOTT W. et al., 2018, Numerical Studies of Improved Methane Drainage Technologies by Stimulating Coal Seams in Multi-Seam Mining Layouts: A Case Study, International Journal of Rock Mechanics and Mining Sciences, accepted for publication.

SZLĄZAK N. et al., 2016, Methane in Polish Coal Mines - Methods of Control and Utilization, Conference: 24th World Mining Congress, Rio de Janeiro.

Visage, GeoQuest, Schlumberger, https:/www.software.slb.com/products/visage, 2017, [accessed: 15 May 2017.

YAN F. et al., 2015, A novel ECBM extraction technology based on the integration of hydraulic slotting and hydraulic fracturing, Journal of Natural Gas Science and Engineering, 22, 571-579. 